\title{
Use of Coal Bottom Ash as Mechanical Stabiliser in Subgrade Soil
}

\author{
Abdus Salaam Cadersa, ${ }^{1}$ Akshay Kumar Seeborun, ${ }^{2}$ and Andre Chan Chim Yuk ${ }^{1}$ \\ ${ }^{1}$ Faculty of Engineering, University of Mauritius, 80837 Reduit, Mauritius \\ ${ }^{2}$ University of Mauritius, 80837 Reduit, Mauritius \\ Correspondence should be addressed to Abdus Salaam Cadersa; a.cadersa@uom.ac.mu
}

Received 9 July 2014; Accepted 7 November 2014; Published 23 November 2014

Academic Editor: Jianjun Zheng

Copyright (c) 2014 Abdus Salaam Cadersa et al. This is an open access article distributed under the Creative Commons Attribution License, which permits unrestricted use, distribution, and reproduction in any medium, provided the original work is properly cited.

\begin{abstract}
This paper presents the laboratory investigation work which forms part of a full scale research road project in Mauritius where coal bottom ash is used as mechanical stabiliser in a saprolitic subgrade soil. Three mixtures of subgrade soil and CBA were investigated in the laboratory, each containing varying percentages of coal bottom ash by weight $(15 \%, 30 \%$, and $40 \%$, resp.). The laboratory research indicated that the mechanical properties of the subgrade soil are improved with the addition of bottom ash. Highest values for soaked and unsoaked CBR values were obtained for the mixture containing $30 \%$ by weight of bottom ash, which were $145 \%$ and $95 \%$, respectively, as compared to $40 \%$ and $55 \%$ for the subgrade soil alone. Upon addition of coal bottom ash, a considerable decrease in swelling potential during soaking was observed for the mixture containing $40 \%$ by weight of CBA. The swell decreased from $0.17 \%$ for the subgrade soil alone to $0.04 \%$ for the mixture containing $40 \%$ by weight of CBA. Moreover, a CBA content of $30 \%$ resulted in a mix of intermediate plasticity as compared to the subgrade soil which is highly plastic. It is concluded that coal bottom ash can be used successfully as a mechanical stabilizer in the experimental subgrade soil by addition of 30 to $40 \%$ of CBA.
\end{abstract}

\section{Introduction}

In Mauritius, in the year 2008, thermal power generation accounted for $96 \%$ of the total energy produced, out of which the contribution of coal as fuel was $45 \%$ and over 105000 tonnes of coal ash were generated [1]. In view of the expected increase in utilization of coal for power generation in the forthcoming decades in Mauritius, ash disposal may become a major environmental problem unless appropriate measures are adopted. In order to address this issue, the government of Mauritius has set up a Technical Advisory Committee (TAC) in 2007 to investigate on the disposal of coal ash in an integrated environment strategy [2]. The TAC concluded that coal ash can be defined as a recyclable by-product of energy production that requires environmental supervision in its use and recommended both encapsulated and unencapsulated applications. The encapsulated uses of coal ash include partial substitute for cement (blending with cement), aggregates for concrete products, mineral filler in asphalt, and controlled low strength materials. The unencapsulated uses of coal ash are fills below roads/buildings/pavements/parking areas, soil stabilization, and material for pipe bedding [3].

Physically, CBA has a semispherical to spherical particle shape and a complex morphology with a rough surface texture [4]. The rough surface and angular shape of the coal bottom ash generally increase particle interlocking and restrict movement from one particle to another, therefore providing mechanical stabilisation to a soil.

Rifa'i et al. [5] recommended the use of coal bottom ash as a mechanical stabiliser for soft soils based on laboratory results showing a rise in California bearing ratio (CBR) values upon addition of a mixture of coal bottom ash and coal fly ash to a soft soil. An optimum CBR rise was observed in the range of 15 to 30 percent of coal fly ash added. Also, a decrease in swelling potential ranging from $14 \%$ to $0 \%$ was observed when using a coal ash content of $45 \%$ by weight of a soft soil. However, addition of ash beyond that percentage reduced the strength of the coal ash mixture. Gray and Lin [6] concluded that properly compacted coal bottom ash met the engineering requirements for load bearing fills and pavement subbases. 
TABLE 1: Laboratory tests carried out and standards used.

\begin{tabular}{lccc}
\hline Test and standard & Subgrade soil & Coal bottom ash & Mixture of subgrade soil and bottom ash \\
\hline $\begin{array}{l}\text { Particle size distribution } \\
\text { BS 1377-2:1990 }\end{array}$ & $\sqrt{ }$ & $\sqrt{ }$ & $\sqrt{\sqrt{ }}$ (only for mixture containing 30\% by weight of CBA) \\
\hline $\begin{array}{l}\text { Particle density } \\
\text { BS 1377-2:1990 }\end{array}$ & $\sqrt{ }$ & & \\
\hline $\begin{array}{l}\text { Atterberg limits } \\
\text { BS 1377-2:1990 }\end{array}$ & $\sqrt{ }$ & & (only for mixture containing 30\% by weight of CBA) \\
\hline $\begin{array}{l}\text { Heavy proctor test } \\
\text { BS 1377:4:1990 }\end{array}$ & $\sqrt{ }$ & $\sqrt{ }$ (for all mixtures) \\
\hline $\begin{array}{l}\text { California bearing ratio } \\
\text { BS 1377:4:1990 }\end{array}$ & $\sqrt{ }$ & & $\sqrt{ }$ (for all mixtures) \\
\hline $\begin{array}{l}\text { Loss on ignition } \\
\text { BS 1377-3:1990 }\end{array}$ & & $\sqrt{ }$ & \\
\hline
\end{tabular}

In line with recommendations of the TAC, laboratory research on the use of coal bottom ash as mechanical stabilizer for subgrade soil in road construction projects has been carried out. Khodabacus [7] assessed whether a mixture of soil and coal bottom ash could be used as capping layer in pavement construction. Two coarse grained soils and one fine grained soil were used in the research. Khodabacus [7] concluded that coal bottom ash is a good stabiliser for soil in enhancing the strength and decreasing the swelling pressure and recommended the use of 30 to $50 \%$ by weight of coal bottom ash to soil as a mechanical stabilizer. Dirpal [8] assessed the effect of coal bottom ash on the mechanical properties of residual soils. Compaction tests and California bearing ratio (CBR) tests were carried out on bottom ash and residual soil mixtures in proportions of $0 \%$ CBA, $20 \%$ CBA, and $40 \%$ CBA to residual soil by weight, respectively. The research showed that as the proportion of bottom ash increased from $0 \%$ to $40 \%$, maximum dry density (MDD) decreased and the soaked CBR value increased from $14 \%$ to 23\% under standard compaction. Dirpal [8] concluded that a mixture of residual soil and bottom ash can be used as an economical engineered fill in embankments, backfills, and road bases.

Seenundun [9] evaluated the use of coal power plant wastes in engineered fills and found that coal bottom ash brought an improvement in the compaction characteristics of a silty soil sample.

It is to be noted that the characteristics of bottom ash can depend on the coal source and plant operations and therefore vary from plant to plant. Hence, the values for the different characteristics reported by researchers apply only to the ash samples tested by those researchers and must not be taken as absolutes.

In 2012, the University of Mauritius in collaboration with the Road Development Authority embarked on the construction of a pilot road stretch where coal bottom ash will be used as mechanical stabilizer in subgrade soil. This paper presents the laboratory research work that has been carried out prior to the design and implementation of the pilot stretch. The objectives of this laboratory investigation were to assess whether the use of the coal bottom ash is technically feasible as mechanical stabilizer for that particular subgrade soil and to determine the optimum mixture proportion of coal bottom ash to subgrade soil that yields the highest CBR value and lowest swelling potential.

\section{Materials and Methodology}

2.1. Materials. Materials used in this laboratory research are disposed coal bottom ash collected from a local thermal power plant located in the eastern region of the island and two subgrade soil samples taken from an experimental stretch of a road construction project. The soil sample was taken at a depth of $750 \mathrm{~mm}$ from the natural subgrade level. The subgrade is a saprolitic soil.

2.2. Laboratory Test and Standards. Laboratory tests were carried out on samples of subgrade soil, coal bottom ash, and mixtures of subgrade soil and bottom ash according to standards as described in Table 1.

2.2.1. Particle Size Distribution. Particle size distribution was carried out for subgrade soil, CBA, and the optimum CBAsoil mix (30\% CBA and 70\% soil mix) samples in accordance with test method BS 1377-2:1990 clause 9.2 and 9.5 [10].

2.2.2. Hydrometer Sedimentation. For the particles passing the $63 \mu \mathrm{m}$ sieve sizes, hydrometer sedimentation method for classifying the CBA and soil samples was adopted in accordance with clause 9.5 of BS 1377-2:1990 [10].

2.2.3. Atterberg Limits. The consistency limit tests were performed on samples of the subgrade soil and on the mixture containing $30 \%$ by weight of CBA in accordance with BS 1377 2:1990 clause 4 [10] to classify the samples in terms of their plasticity index. The liquid limit was determined through the cone penetrometer test.

Limits for the coal bottom ash were not determined since the CBA is a nonplastic material. 
2.2.4. Particle Density. The particle density of the subgrade soil and CBA samples were performed according to BS 13772:1990 clause 8.3 (small pycnometer method) [10].

2.2.5. Dry Density and Moisture Content Relation. The test was performed in accordance with clause 6.4.2 of BS 1377:4:1990 [10] on air-dried coal bottom ash and soil samples. The maximum dry density and the optimum moisture content were determined in a CBR mould using a $4.5 \mathrm{~kg}$ hand rammer.

$0 \%, 15 \%, 30 \%$, and $40 \%$ by weight of coal bottom ash were added to subgrade soil. Each of the four specimens was compacted in 5 layers, with each layer receiving 62 blows. Owing to the local crushing of the CBA, fresh samples of coal bottom ash and subgrade soil were used for every test.

2.2.6. California Bearing Ratio Test. The California bearing ratio test was carried out as per BS 1377:4:1990 clause 7 [10] on samples of subgrade soil and mixtures of subgrade soil and coal bottom ash [10].

For CBR testing, the samples were air dried and pretreated for compaction as per clause 7.2 of BS 1377:4:1990 [10]. Since the field CBR value is expected to lie within the range of laboratory 4-day soaked and unsoaked CBR values due to the fact that the equilibrium moisture content of the field subgrade soil lies between the moisture content of the soaked and unsoaked conditions, the subgrade soil and mixtures containing $15 \%, 30 \%$, and $40 \%$ by weight of coal bottom ash mixes were subjected to CBR tests both in the unsoaked and soaked conditions.

2.2.7. Loss on Ignition. The loss on ignition test was performed on the CBA samples in accordance with BS 13773:1990 clause 4.3 [10].

\section{Results and Discussion}

\subsection{Subgrade Soil}

3.1.1. Classification of Soil Sample. The subgrade soil sample had light reddish brown colour and had a rough surface texture with some gravel sized particles and cobbles. The particle size distribution of the soil is given in Figure 1.

The effective diameter $\left(D_{10}\right)$ of the particles is $0.02 \mathrm{~mm}$. The uniformity and gradation coefficients are 138.89 and 4.01, respectively. The fine fraction had a liquid limit of $60 \%$ and a plastic limit of $36 \%$. According to the British Soil Classification System, the soil sample can be classified as a well-graded sandy GRAVEL with some silt. The saprolitic soil was formed from the weathering of basaltic rocks.

3.1.2. Moisture-Density Relationship. A relatively high specific gravity value, $G_{s}$ of 2.88 , was obtained for the saprolitic soil. A maximum dry density of $1612 \mathrm{~kg} / \mathrm{m}^{3}$ corresponding to an optimum moisture content of $25.7 \%$ was observed, as shown in Figure 2.

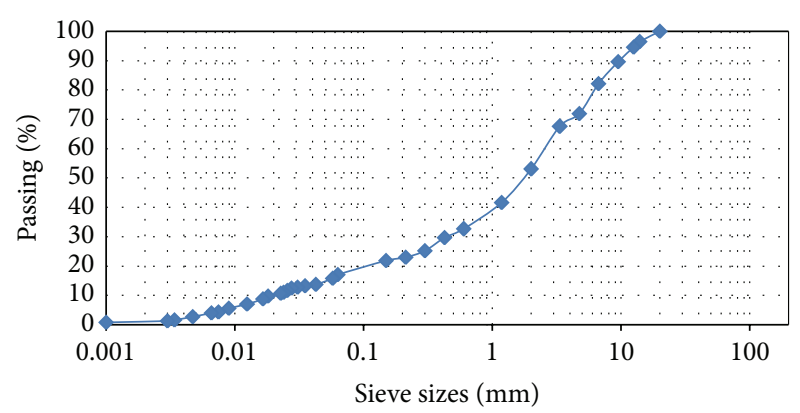

Figure 1: Particle size distribution of subgrade soil.

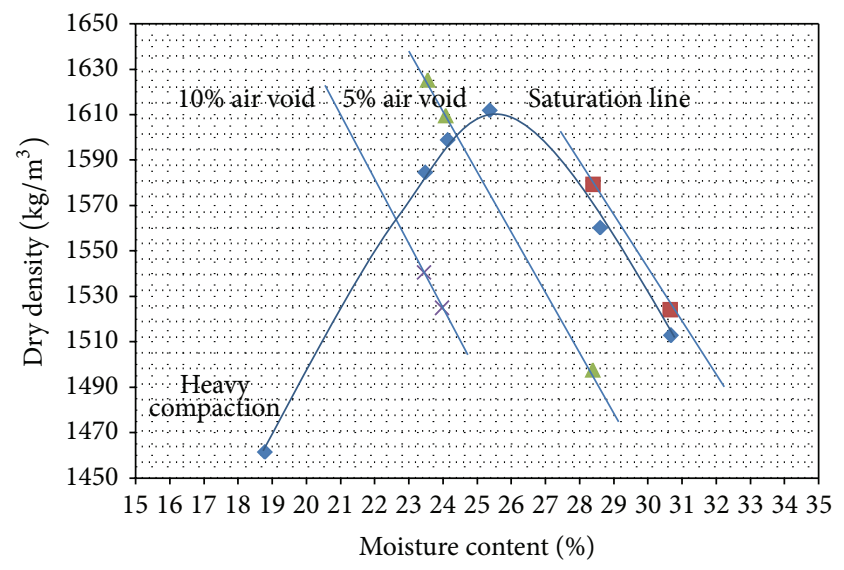

FIGURE 2: Compaction curve for subgrade soil.

3.1.3. California Bearing Ratio and Swelling. The CBR value of unsoaked soil sample was obtained as $55 \%$ at a compacted dry density of $1560 \mathrm{~kg} / \mathrm{m}^{3}$ and at a corresponding moisture content of $28.7 \%$. The CBR value lies in the range of $20-50 \%$ suggested by Look [11] for well-graded sand gravel soils. The 4-day soaked CBR obtained was $50 \%$ at a compacted bulk density of $1586 \mathrm{~kg} / \mathrm{m}^{3}$ and at a moisture content of $27.2 \%$. A swelling of $0.17 \%$ was observed at the end of the 4 -day soaking procedure, which is desirable for pavement construction. Moreover, the compaction was already achieved in the range of 0 to $5 \%$ air void ratio that is near saturation.

\subsection{Coal Bottom Ash}

3.2.1. Classification of Coal Bottom Ash. The coal bottom ash was collected from a local power plant and was a dark gray angular coarse material with some popcorn like materials. The particle distribution curve for the ash is given in Figure 3.

The effective size $\left(\mathrm{D}_{10}\right)$ of coal bottom ash particles is $0.10 \mathrm{~mm}$ and the uniformity and gradation coefficients are 47.5 and 3.56, respectively, which correspond to a well-graded soil [12]. The coal bottom ash can be categorised as per the British Standard Soil Classification as a well-graded sandy GRAVEL since more than $35 \%$ of the soil fraction is greater than $0.06 \mathrm{~mm}$. Moreover, the coal bottom ash exhibited nonplastic behaviour. 


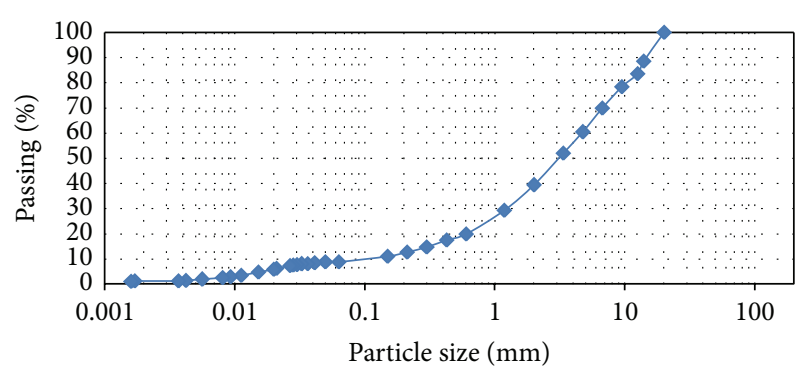

FIGURE 3: Particle size distribution of coal bottom ash sample.

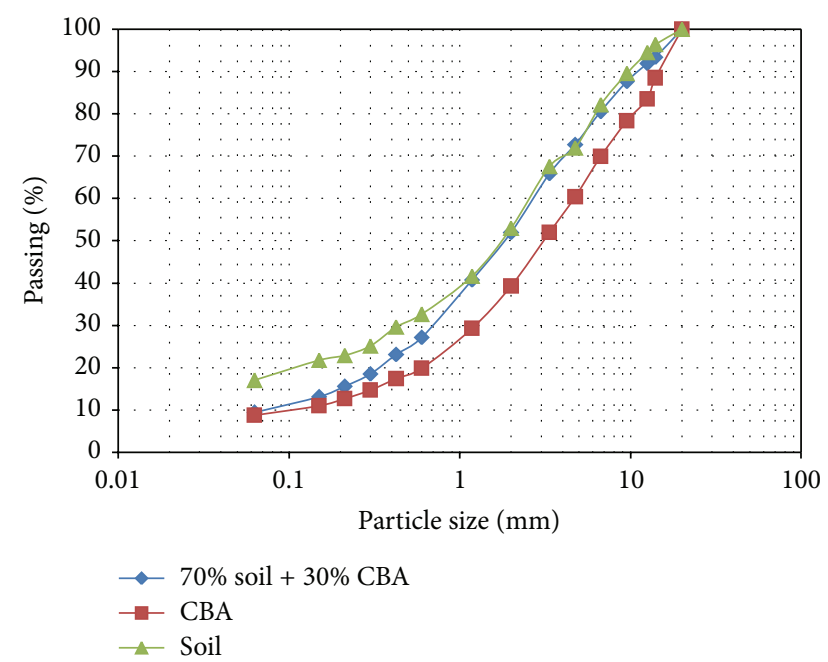

FIgURE 4: Particle size distribution comparison for soil, CBA, and soil-CBA mix.

3.2.2. Loss on Ignition. The loss on ignition (LOI) test yielded a value of $3.2 \%$ for the coal bottom ash sample. The LOI value for CBA is almost similar to that obtained by Seenundun [9]. As per the British Standard designation, the LOI test is performed on sample with particle size less than $2.00 \mathrm{~mm}$ and pulverized through $425 \mu \mathrm{m}$ to ensure that the entire sample is ignited with a higher surface area exposed.

\subsection{Mixture of Subgrade Soil and Coal Bottom Ash}

3.3.1. Particle Size Distribution Comparison. Addition of bottom ash to the subgrade soil resulted in a mixture having a better graded particle size distribution than the constituent soils. This is illustrated in Figure 4 whereby the grading curve of the $30 \%$ CBA to $70 \%$ soil by weight mixture lies at an intermediate position with respect to the grading curves of the subgrade soil and coal bottom ash. Therefore, stability and mechanical strength of the coal bottom ash and subgrade soil mixture are increased, until a maximum is reached corresponding to the optimum proportion of $30 \% \mathrm{BA}: 70 \%$ subgrade soil.

In addition, the mixture containing $30 \%$ by weight of CBA had a plastic limit of $22 \%$, a liquid limit of $50 \%$, and thus a plasticity index of $28 \%$. The soil mixture can therefore be classified as a soil of intermediate plasticity (L.L between 35\%

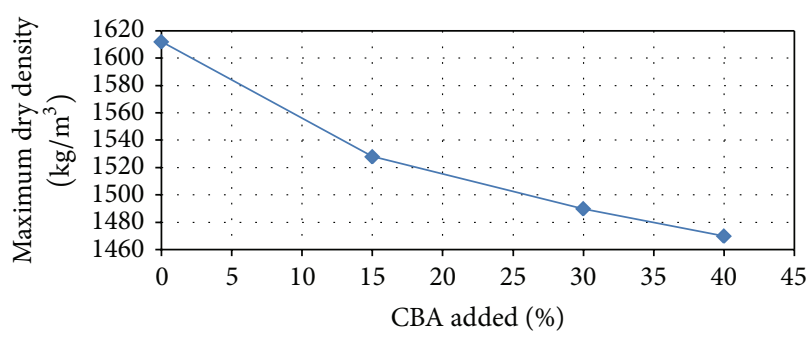

FIgURE 5: Trend of maximum dry density with increasing coal bottom ash content.

and $50 \%$ ), which is more desirable as a subgrade material compared to the subgrade soil only which is highly plastic.

3.3.2. Moisture-Density Relationship. Upon addition of coal bottom ash in increasing proportions to the soil by weight, the maximum dry density decreased as illustrated in Figure 5.

This is in line with findings of Khodabacus [7] who reported a drop in MDD from $1440 \mathrm{~kg} / \mathrm{m}^{3}$ to $1338 \mathrm{~kg} / \mathrm{m}^{3}$ upon addition of CBA obtained from a local power plant to coarse gravel soil under modified compaction tests. Usually, coal bottom ashes exhibit lower maximum dry densities (MDD) compared to conventional granular aggregates which may be a result of the lower specific gravity of coal bottom ash $[7,9,13]$. In this research, the particle density of coal bottom ash was $2.22 \mathrm{Mg} / \mathrm{m}^{3}$, lower than that of the soil which is $2.88 \mathrm{Mg} / \mathrm{m}^{3}$ such that the combined MDD of the CBA and subgrade soil mixture decreased with increasing CBA content.

Moreover, a decrease in the optimum moisture content is observed from an optimum moisture content of $25.7 \%$ with the subgrade soil compared to an optimum moisture content of $22.8 \%$ with $60 \%$ soil and $40 \%$ CBA mix. This decline may be occurring due to the nonplastic nature of the coal bottom ash. Since coal bottom ash has a higher void ratio at around 5 to $15 \%$ compared to soil at maximum dry density, which is around 1 to $5 \%$ [14], there is an increase in the void ratio of the subgrade soil and CBA mixture which ranges from $5 \%$ to $10 \%$, depending on the CBA content. Consequently, water absorption into these voids is most probable, leading to a decrease in moisture content.

Rogbeck and Knutz [15] state that laboratory compaction curves for coal bottom ash generally exhibit lower optimum moisture content, demonstrating the insensitivity of coal bottom ash to water.

3.3.3. CBR Values with Addition of CBA. The variation of the CBR value with coal bottom ash content in the soil is shown in Figure 6.

Addition of coal bottom ash generally increases the CBR value until reaching a maximum $30 \%$ coal bottom ash by weight, where both the soaked and unsoaked CBR values are the highest. This is due to the fact that addition of CBA leads to an increasingly well-graded particle size distribution as shown in Figure 4, such that particles of soil and ash particles get more closely packed together. This causes an increase 


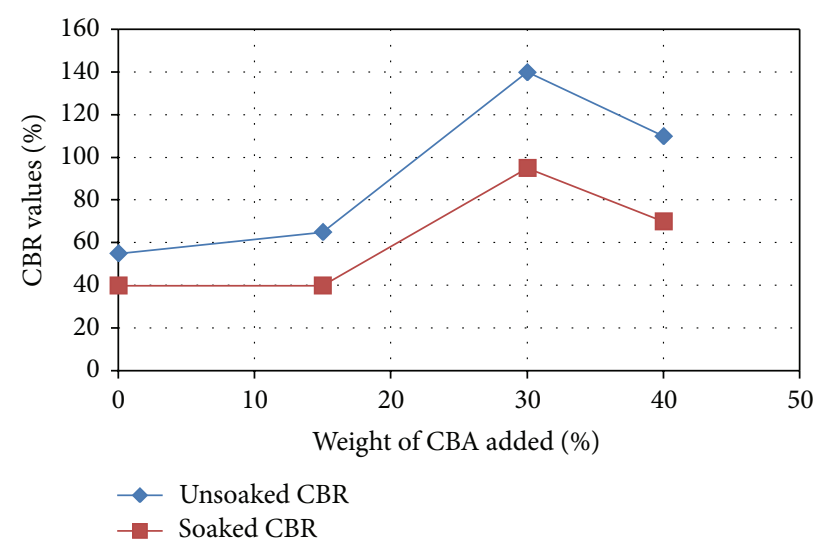

FIGURE 6: Graph of soaked and unsoaked CBR values with increasing CBA content.

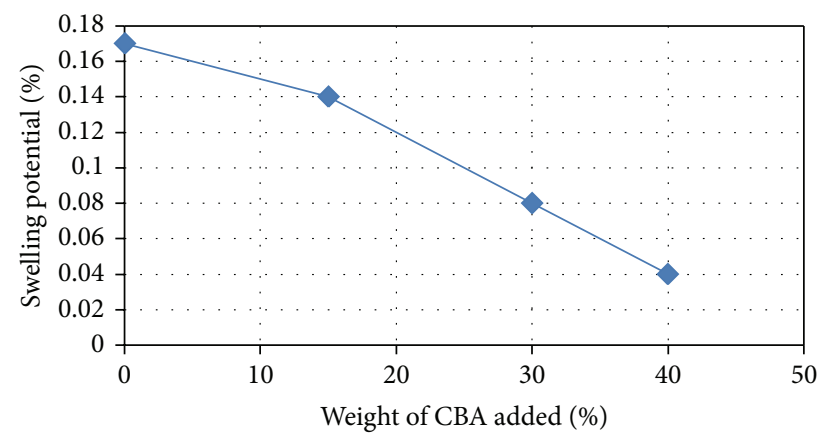

FIGURE 7: Graph showing swelling potential (\%) with increasing CBA content (\%).

in the mechanical strength. Moreover, during compaction, the coal ash particles undergo a certain degree of local crushing thus further filling up the voids and increasing cohesion. The decrease in the void ratio eventually increases the bearing capacity. However, a further increase in the CBA content causes the CBR value to decrease since the particle size of coal bottom ash starts to predominate the size distribution of the mix. Eventually, with more coarse particles, an increase in particle interference is caused which restricts the rearrangement of the mix particles into a closely packed arrangement. Cohesive and bonding forces are also minimal due to a decrease in fine content.

3.3.4. Trend in Swelling Characteristics. The effect of coal bottom ash content on the swelling potential is graphically illustrated in Figure 7. Upon addition of coal bottom ash, a considerable decrease in swelling potential is observed, namely, a decrease from $0.17 \%(0 \%$ CBA) to $0.04 \%(40 \%$ CBA), which is in line with findings of Rifa'i et al. [5] and Khodabacus [7].

\section{Conclusions and Recommendations}

The results obtained from the laboratory investigation confirm the general findings from previous research that adding
CBA to subgrade soil increases CBR value and decreases the swelling potential. In addition, as expected, a decrease in MDD upon addition of CBA to the soil was registered due to a lower specific gravity of the CBA.

The investigation also demonstrates that CBA may effectively be used as a mechanical stabilizer for the subgrade soil on the pilot field stretch and that $30 \%$ by weight of CBA added to the subgrade soil yielded the highest unsoaked and soaked CBR values of $140 \%$ and $95 \%$, respectively. The swelling potential decreased from $0.17 \%$ to $0.04 \%$ due to a decrease in the fine portion of the soil by the addition of well-graded coarse sandy gravel CBA particles. Moreover, at a CBA content of $30 \%$, the soil is of intermediate plasticity which is more desirable than the subgrade soil which is highly plastic. It is therefore recommended to use a mixture of CBA : subgrade soil of $30: 70 \%$ for the pilot stretch.

\section{Conflict of Interests}

The authors declare that there is no conflict of interests regarding the publication of this paper.

\section{References}

[1] MREPU, Ministry of Renewable Energy \& Public Utilities, 2009, Long-Term Energy Strategy 2009-2025, Government Printing Office, 2009.

[2] Ministry of Environment \& Sustainable Development (MESD), "Technical advisory committee on coal ash management," Final Report, 2009.

[3] MTESRT, "Ministry of Tertiary Education Scientific Research \& Technology," Status Report on Research on Coal Ash Management in Mauritius, 2010.

[4] R. K. Seals, L. K. Moulton, and B. E. Ruth, "Bottom ash: an engineering material," Journal of the Soil Mechanics and Foundations Division, vol. 98, no. 4, pp. 311-325, 1972.

[5] A. Rifa'i, N. Yasufuku, K. Omine, and K. Tsuji, "Experimental study of coal ash utilisation for road application on soft soil," in Proceedings of the International Joint Symposium on Geodisaster Prevention and Geoenvironment, Fukuoka, Japan, September 2009.

[6] D. H. Gray and Y. Lin, "Properties of compacted fly ash," ASCE Journal of Soil Mechanics and Foundations Division, vol. 98, no. 6, pp. 361-381, 1972.

[7] R. Khodabacus, The effect of coal bottom ash on soil properties [Ph.D. thesis], University of Mauritius, 2012.

[8] S. Dirpal, Evaluation of coal bottom ash and residual soil mixtures as engineered fills [Thesis], University of Mauritius, 2013.

[9] D. Seenundun, Evaluation of power plant wastes in engineered fills [M.S. thesis], University of Mauritius, 2013.

[10] British Standards Institution, Methods of Test for Soil for Civil Engineering Purposes: BS 1377, British Standards Institution, London, UK, 1990.

[11] B. Look, Handbook of Geotechnical Investigation and Design Tables, Taylor \& Francis/Balkema, Leiden, The Netherlands, 2007.

[12] R. F. Craig, Soil Mechanics, Van Nostrand Reinhold, Wokingham, UK, 4th edition, 1987. 
[13] T. B. Edil, C. H. Benson, M. S. Bin-Shafique, B. F. Tanyu, W. Kim, and A. Senol, "Field evaluation of construction alternatives for roadways over soft subgrade," Journal of Transportation Research Record, vol. 1786, no. 1, pp. 36-48, 2002.

[14] P. S. Toth, H. T. Chan, and C. B. Cragg, "Coal ash as structural fill, with special reference to Ontario experience," Canadian Geotechnical Journal, vol. 25, no. 4, pp. 694-704, 1988.

[15] J. Rogbeck and A. Knutz, "Coal bottom ash as light fill material in construction," Waste Management, vol. 16, no. 1-3, pp. 125128, 1996. 

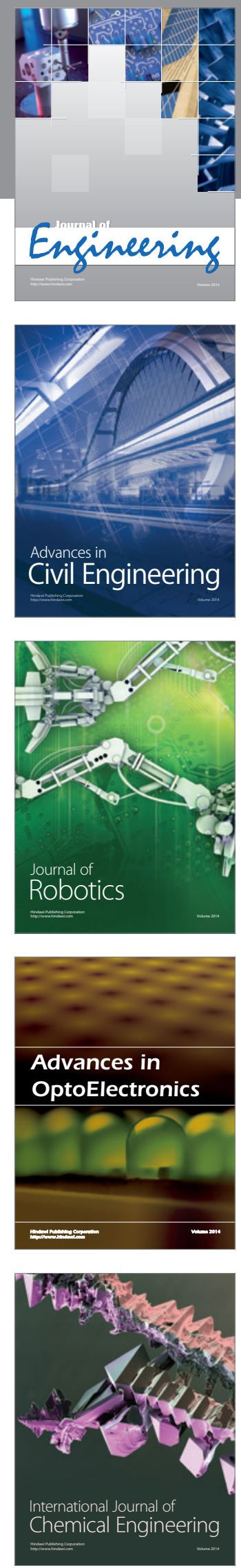

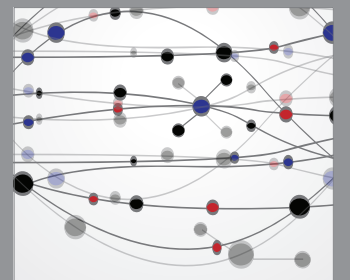

The Scientific World Journal
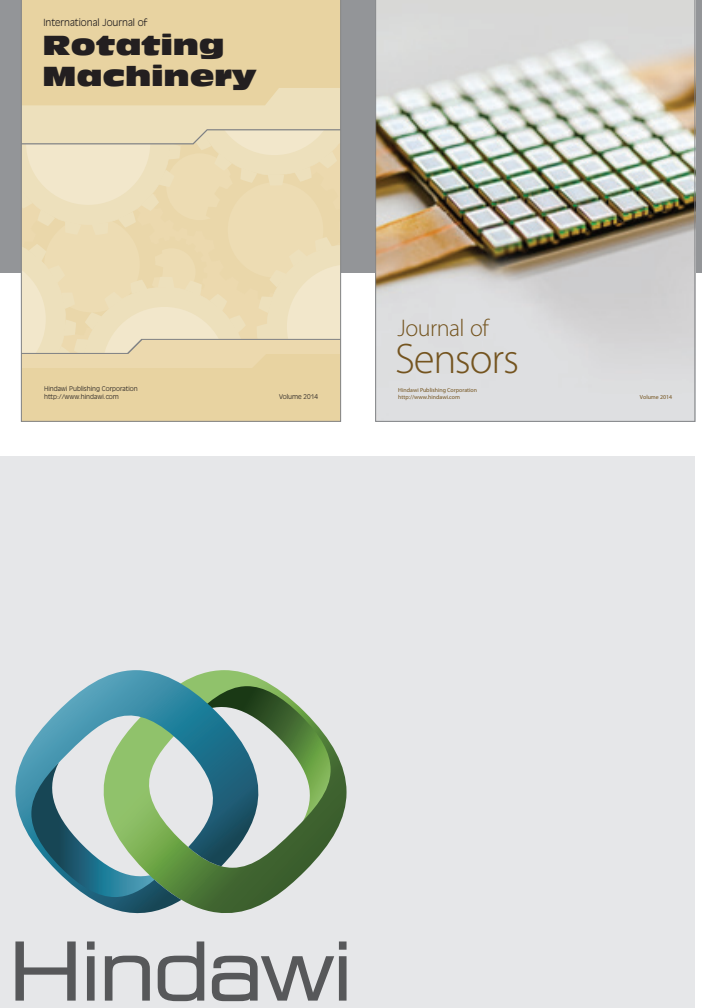

Submit your manuscripts at http://www.hindawi.com
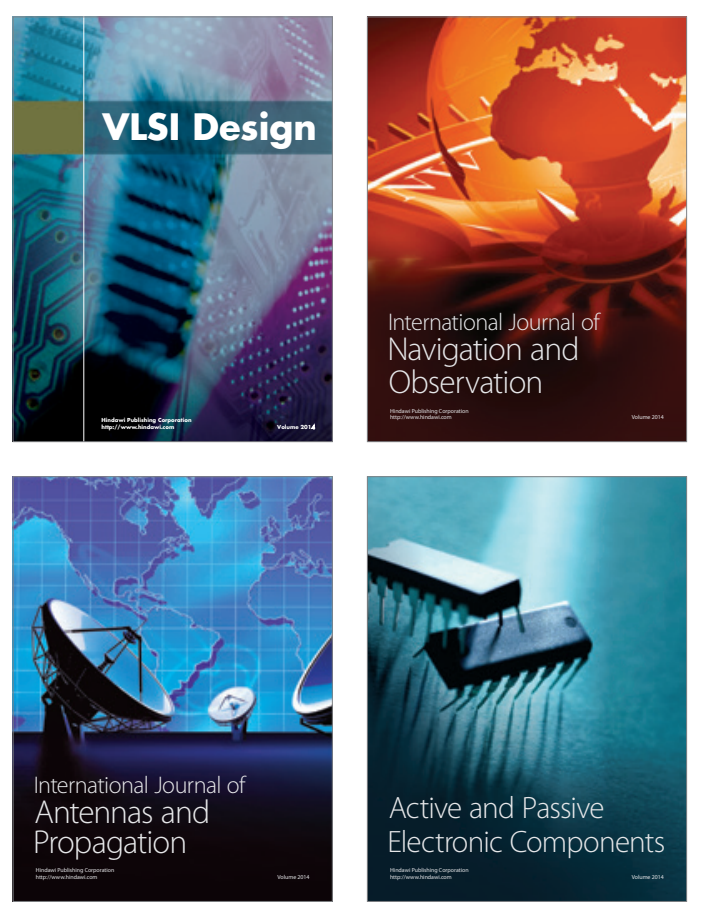
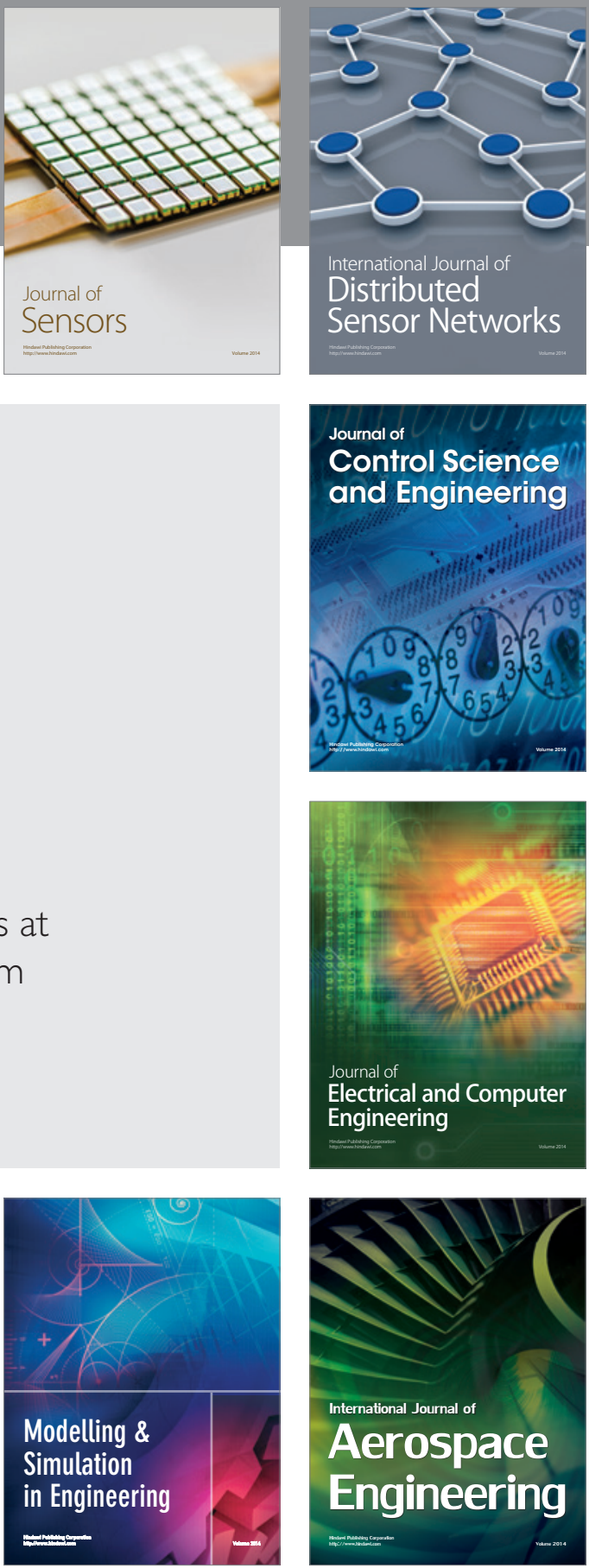

Journal of

Control Science

and Engineering
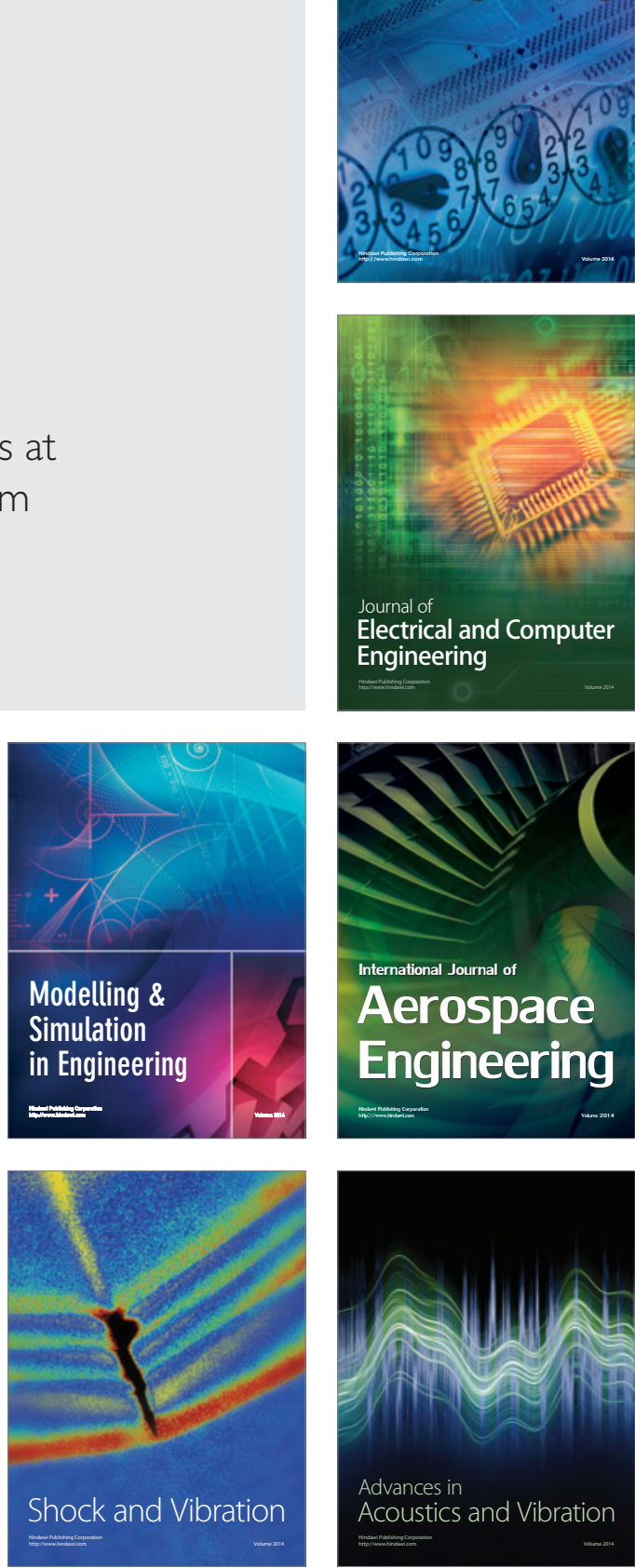